\title{
Nursing-Intense Health Education Intervention for Persons with Type 2 Diabetes: A Quasi-Experimental Study
}

\author{
María Begoña Martos-Cabrera ${ }^{1}$, José Luis Gómez-Urquiza ${ }^{2} \mathbb{D}$, Guillermo Cañadas-González ${ }^{3}$, \\ José Luis Romero-Bejar ${ }^{4 *} * \mathbb{D}$, Nora Suleiman-Martos ${ }^{2} \mathbb{D}$, Guillermo Arturo Cañadas-De la Fuente 2 (D) \\ and Luis Albendín-García ${ }^{5}$ (D)
}

Citation: Martos-Cabrera, M.B.; Gómez-Urquiza, J.L.;

Cañadas-González, G.; Romero-Bejar,

J.L.; Suleiman-Martos, N.;

Cañadas-De la Fuente, G.A.;

Albendín-García, L. Nursing-Intense Health Education Intervention for Persons with Type 2 Diabetes: A Quasi-Experimental Study. Healthcare 2021, 9, 832. https://doi.org/ $10.3390 /$ healthcare 9070832

Academic Editor: Pedram Sendi

Received: 2 June 2021

Accepted: 25 June 2021

Published: 1 July 2021

Publisher's Note: MDPI stays neutral with regard to jurisdictional claims in published maps and institutional affiliations.

Copyright: (c) 2021 by the authors. Licensee MDPI, Basel, Switzerland. This article is an open access article distributed under the terms and conditions of the Creative Commons Attribution (CC BY) license (https:// creativecommons.org/licenses/by/ $4.0 /)$.
1 Neonatal Intensive Care Unit, University Hospital San Cecilio, Avenida del Conocimiento, 18016 Granada, Spain; begomartos90@gmail.com

2 Faculty of Health Sciences, University of Granada, Avenida de la Ilustración, 60, 18016 Granada, Spain; jlgurquiza@ugr.es (J.L.G.-U.); norasm@ugr.es (N.S.-M.); gacf@ugr.es (G.A.C.-D.1.F.)

3 Support Device South Area of Cordoba, Andalusian Health Service, Av. Góngora, 9B, Cabra, 14940 Córdoba, Spain; benaldoctor@hotmail.com

4 Department of Statistics and Operational Research, University of Granada, 18071 Granada, Spain

5 Casería de Montijo Health Center, Granada Metropolitan District, Andalusian Health Service, Calle Virgen de la Consolación, 12, 18015 Granada, Spain; lualbgar1979@ugr.es

* Correspondence: jlrbejar@ugr.es

\begin{abstract}
Type 2 diabetes mellitus (DM2) is a highly prevalent disease, the progression of which depends on high blood glucose levels, which are reflected in the level of glycosylated haemoglobin (HbA1c). Appropriate health education equips patients with the knowledge and skills to control their glucose and $\mathrm{HbA1c}$ levels to avoid long-term complications. This study was set up to compare the results of an intensive (360 $\mathrm{min}$ ) educational intervention to improve $\mathrm{HbA1c}$ parameters in patients with DM2 with those of a usual 90 min intervention. For this purpose, healthcare personnel led a quasi-experimental study of 249 diabetics: 171 in the control group, and 78 in the intervention group. In the control group, the mean $\mathrm{HbA1c}$ value decreased from 6.97 to 6.75 , while in intervention group it fell from 8.97 to 8.06 . The before and after mean difference between both groups was compared with a Wilcoxon test, and the results statistically significant $(\mathrm{W}=4530 ; p<0.001)$, indicating a higher reduction of $\mathrm{HbA} 1 \mathrm{c}$ in the intervention group. We concluded that the intensive health education provided by nurses during the consultation helped improve HBA1c levels in persons with DM2.
\end{abstract}

Keywords: clinical trial; diabetes mellitus type 2; HbA1c; health education; primary care

\section{Introduction}

The American Diabetes Association defines diabetes mellitus (DM) as a group of metabolic diseases characterised by hyperglycaemia resulting from defects in insulin secretion, insulin action, or both. Chronic hyperglycaemia of diabetes is associated with long-term damage [1,2].

According to the aetiology of chronic hyperglycaemia, diabetes mellitus is classified as type 1 (DM1), type 2 (DM2) or gestational (DMG). DM1 is characterised by the absence of insulin secretion by an autoimmune process [1-4]. DM2 arises from a defect in the effect of insulin in the tissues or in their resistance to it, and the majority of patients are overweight $[1,3,5,6]$.

Between 1980 and 2014, the prevalence of DM2 rose from 4.7 to $8.5 \%$, and premature mortality due to DM increased by 5\%, making it the seventh cause of death in 2016. It is estimated that by 2030366 million patients worldwide will have DM. In Europe, the prevalence is expected to increase by 16\% between 2017 and 2045 [7,8]. In 2016, 13.8\% of the Spanish adult population had DM2 according to the di@betes.es study (conducted in Spain) [7]. Given the age and sex composition of the population, an incidence of 11.6 cases 
per 1000 inhabitants per year was estimated, which corresponded to 3.7 cases $/ 1000$ inhabitants/year of known diabetes symptoms and 7.9 cases/1000 inhabitants/year of unknown symptoms [7,8].

Between 90 and $95 \%$ of patients with DM are classified as type 2 . The majority are between 50 and 60 years and overweight. The disease may be triggered by various environmental factors [1,9-12], most of which are modifiable, meaning that DM2 is potentially preventable. Accordingly, by addressing these factors the disease can be controlled both to improve the patient's quality of life and prevent secondary pathologies arising from inadequate blood glucose management [3,7,12].

Among the many risk factors for DM2 is being overweight or obese, with the latter contributing the most to the development of insulin resistance [12]. Family history, hypertension, dyslipidaemia and age are also relevant, with those over 45 years having a higher probability of presenting the disease [7]. Moreover, a personal history of DMG increases the possibility of developing DM2 by up to 10 times compared to pregnant women with normal blood sugar levels [13]. Finally, an inadequate diet or a sedentary lifestyle also increase the risk of DM2 [1,3,5,7,14].

The usual treatment for DM2 is focused on ensuring that blood glucose remains within appropriate bounds. This parameter is measured by the glycosylated haemoglobin (HbA1c) test, which provides recent data on fluctuations in blood glucose levels (usually, the last three months). The target value for good glycaemic control in patients with DM2 is $\mathrm{HbA} 1 \mathrm{c}<7 \%[15,16]$.

To achieve the recommended $\mathrm{HbA} 1 \mathrm{c}$ level, patients with $\mathrm{DM} 2$ are given treatment to maintain or achieve normoglycaemia. This treatment is both pharmacological, based on subcutaneous insulin and oral medication, and non-pharmacological through education, nutrition and physical exercise. Information about these approaches is provided during doctor-patient consultations, and support material, such as mobile applications and games, can be used to facilitate learning and management [17-21].

Determining and conducting the interventions for controlling glycaemia in these patients may be complex. The process requires knowledge of the disease and the ability to perform the prescribed treatment. Therefore, health education is of vital importance for patients with DM2. In fact, the risk of mortality is inversely related to the patient's understanding of the disease [22].

Previous studies with Health Education interventions have focused mainly on adherence to good nutritional habits, such as the Mediterranean diet [23], which improves $\mathrm{HbA1c}$. Other positive results stem from interventions like personalized nutrition [24], adequate knowledge about counting carbohydrates [25] and consulting nutritionists [26].

Other studies have focused on interventions led by nursing staff [27], therapy relating to acceptance and of the disease and a commitment to lessening it [28] and self-care support [29] by reporting health improvements.

Providing information and treatment procedure training during consultations, according to the patient's understanding, can lower HbA1c levels, which can also prevent pathologies such as retinopathy, nephropathy and neuropathy $[5,15,30]$.

In this context, the patient is not only informed about the disease, but is also shown the technique and frequency of blood glucose measurement, medication administration, the importance of suitable nutrition, and the benefits of physical exercise. Therefore, it is vital that this consultation be conducted by trained physicians and nurses since all interventions must be integrated for global treatment [31].

In short, the aim of our study is to determine whether the provision of an intensive health education programme by healthcare personnel improves $\mathrm{HbA1c}$ parameters in patients with DM2. 


\section{Materials and Method}

\subsection{Design and Participants}

From 1 July 2019 to 31 January 2020, a quasi-experimental study with a control group was performed to compare basic and intensive systematic interventions with the usual care offered at primary care clinics of the Andalusian Health Service (Spain). The reference value taken was the prevalence of DM2 as determined by the epidemiological analysis of the comprehensive diabetes care plan conducted in Andalusia prior to 2019 [30,31].

Our analysis of the results was based on a conservative measurement of each case, and the expectation that the non-systematic intervention control group would obtain only limited benefit, compared with significantly greater improvements for the two intervention groups $[15,22,32]$. Patients with higher $\mathrm{HbA1c}$ levels were included in the intervention group intentionally because, according to previous studies, they could acquire early glycaemic control and delay the introduction of oral antidiabetic drugs, according to the II Comprehensive Diabetes Plan of Andalusia [33].

The patient's condition was classified as DM2, if he or she was older than 30 and presented any of the following criteria: overweight or obesity, insidious onset, absence of ketonuria / ketonaemia, family history of DM2, or a personal history of DMG; otherwise, the condition was classified under "other types of diabetes" $[1,3,5,13]$.

The study population was 291 patients, but the final sample was composed of 249 with DM2 (171 in the control group and 78 in the intervention group) because some patients refused to participate. They were recruited consecutively according to their order of receiving attention at the clinic until the previously established sample size was obtained (calculated according to the total number of diabetic patients in the health area). These patients were referred from nursing or medical consultations by qualified healthcare professionals at each location. Patients with very high $\mathrm{HbA1c}$ levels $(>7 \%)$ were assigned to intervention group, and the rest were assigned to the control group $[3,15]$. Thus, the selection process was intentional.

\subsection{Inclusion Criteria}

All participants were diagnosed with DM2 at primary health care centres in Andalusia and were stratified by age and type of diabetes. All participants were treated in the Granada-Metropolitan Health District for the duration of the study, received the requisite $\mathrm{HbA} 1 \mathrm{c}$ tests, and agreed to remain in the study for approximately six months, attending all scheduled control visits and receiving the appropriate interventions.

\subsection{Interventions Performed and Study Groups}

The interventions for the control and the intervention group were performed during individual sessions by the same two nurses, who had been working with people with diabetes for more than 10 years and who also had postgraduate training in diabetes management. The characteristics of the usual care for the control group and the intensive education intervention for the intervention group are listed below.

Control group (patients with HbA1c levels $<7 \%$ ):

- 15 min scheduled consultation plus group support, every 15 days for 3 months

- $\quad$ Education for health in diabetes: diet and exercise.

- Nursing care plan.

- $\quad$ Examination of sensitivity to pressure and vibration in both feet.

- HbA1c analysis after 6 months.

Intervention group (patients with $\mathrm{HbA1c}$ levels $>7 \%$ ):

- $\quad 30$ min scheduled consultation plus group support, every 7 days for 3 months

- Education for health in diabetes: improved self-care techniques in relation to the complications of poorly controlled diabetes.

- $\quad$ Diet and exercise.

- Nursing care plan: assessment and evolution of nursing objectives. 
- Determination of the ankle-brachial index.

- Detection of vascular complications by anamnesis and examination.

- $\quad$ Screening for diabetic retinopathy: digital retinography.

- $\quad H b A 1 c$ analysis after 6 months

\subsection{Variables and Data Collection}

Sociodemographic data (age and sex) and health outcomes (body mass index, presence of hypertension, retinopathy, neuropathy and diabetic foot risk) were collected at baseline at the first education sessions. Also, 6 months after the intervention, HbA1c was collected through a blood analysis.

\subsection{Statistical Analysis}

SPSS version 20 was used for all statistical analyses. Mean and standard deviation were used for description of continuous variables and frequencies for qualitative variables. A Wilcoxon test for related samples was used for a before-and-after means comparison because the variables did not follow a normal distribution. The mean reduction between both groups was compared with the Wilcoxon test.

\section{Results}

The control group sample was $n=171$ and the intervention group's was $n=78$. The control mean age was 65.32 (SD 13.45) and the intervention mean age was 63.93 (SD 11.18). Regarding body mass index, the control mean was 29.95 (SD 5.35) and intervention mean was 30.57 (SD 5.49). In the control group, the mean $\mathrm{HbA1c}$ value pre intervention was 6.97 (SD 1.36) and for the intervention group, 8.97 (SD 1.60). The other characteristics at baseline are shown in Table 1.

Table 1. Characteristics at baseline.

\begin{tabular}{|c|c|c|c|c|}
\hline \multicolumn{2}{|c|}{ Variable } & \multirow{3}{*}{$\begin{array}{c}\text { Control Group }(n=171) \\
55 \% \\
45 \%\end{array}$} & \multirow{3}{*}{$\begin{array}{c}\text { Intervention Group } 2(\boldsymbol{n}=\mathbf{7 8}) \\
\begin{array}{c}61.4 \% \\
38.6 \%\end{array}\end{array}$} & \multirow{3}{*}{$\frac{p}{p<0.05}$} \\
\hline & Male & & & \\
\hline Sex & Female & & & \\
\hline \multirow{2}{*}{ Hypertension } & Yes & $63.3 \%$ & $59.3 \%$ & \multirow{2}{*}{$p>0.05$} \\
\hline & No & $36.84 \%$ & $40.7 \%$ & \\
\hline \multirow{2}{*}{ Retinopathy } & Yes & $17.5 \%$ & $22.2 \%$ & \multirow{2}{*}{$p<0.05$} \\
\hline & No & $82.5 \%$ & $77.8 \%$ & \\
\hline \multirow{2}{*}{ Neuropathy } & Yes & $28.1 \%$ & $67.9 \%$ & \multirow{2}{*}{$p<0.05$} \\
\hline & No & $71.9 \%$ & $32.1 \%$ & \\
\hline \multirow{3}{*}{$\begin{array}{l}\text { Diabetic } \\
\text { foot }\end{array}$} & Normal & $66.7 \%$ & $60.5 \%$ & \multirow{3}{*}{$p<0.05$} \\
\hline & Risk & $25.7 \%$ & $30.9 \%$ & \\
\hline & High risk & $7.6 \%$ & $8.6 \%$ & \\
\hline
\end{tabular}

$p=p$ value comparison at baseline.

After the intervention, the mean $\mathrm{HbA1c}$ value in the control group was 6.75 (SD 0.84) and 8.06 (SD 1.40). in the intervention group. The analysis showed that in both groups there was a significant reduction in HbA1c levels (Table 2).

Table 2. HbA1c Means pre and post intervention.

\begin{tabular}{cccccc}
\hline Group & $\begin{array}{c}\text { Pre- } \\
\text { Intervention }\end{array}$ & $\begin{array}{c}\text { Post- } \\
\text { Intervention }\end{array}$ & $\begin{array}{c}\text { Mean Difference, Pre } \\
\text { and Post }\end{array}$ & W & $\boldsymbol{p}$ \\
\hline Control & 6.97 (SD 1.36) & 6.75 (SD 0.84) & 0.22 & 1872 & $<0.001$ \\
Intervention & 8.97 (SD 1.60) & 8.06 (SD 1.40) & 0.91 & 2704 & $<0.001$ \\
\hline
\end{tabular}

$\mathrm{df}=$ Degrees of freedom; $p=p$ value; $\mathrm{SD}=$ Standard deviation; $\mathrm{W}=$ Wilcoxon test.

The pre- and post-intervention mean difference in both groups was compared with the Wilcoxon test, and the results were statistically significant $(\mathrm{W}=4530 ; p<0.001)$, indicating a higher reduction of $\mathrm{HbA} 1 \mathrm{c}$ in the intervention group. 


\section{Discussion}

The effective monitoring and management of DM2 is of the utmost importance. It has been estimated that for every $1 \%$ by which $\mathrm{HbA} 1 \mathrm{c}$ is reduced in patients with poorly controlled DM2, the probability of premature death falls by $21 \%$ and that of microvascular complications by $37 \%$. The duration of DM2 is also associated with premature death from cardiovascular disease [34-36].

Therefore, health education is vital and must be in accordance with each patient's education and understanding of the disease and its different concepts. In this respect, a low level of education has been related to the insufficient consumption of whole grains and thus to an increased risk of DM2-related complications [34,37].

In view of these considerations, any programme aimed at instructing DM2 patients on self-care and independence should take into account the patient's understanding of the question. Although most studies of such initiatives have failed to observe a statistically significant improvement in $\mathrm{HbA} 1 \mathrm{c}$, there have been improvements at the psychosocial level [38]. Some patients may follow the recommendations of health professionals for a short time, but in the absence of a long-term follow-up and proper management, the improvement will not persist $[39,40]$. Similar outcomes have been observed among patients with other pathologies, which underlines the view that a health education programme requires follow-up to maintain its initial benefits [41].

Studies have shown that intensive, appropriate health education for DM2 patients leads to improved $\mathrm{HbA1c}$ levels, and that a multidisciplinary team, in which nurses personalise the intervention and facilitate communication [42,43] is essential for its success. Nurses also foster the patient's ability to self-manage the disease, and this not only promotes effective decision making to achieve clinical targets, such as improving blood sugar levels, but it also contributes to reducing disease-related distress [42,44-46]. Previous research in this field has also shown that the role played by nurses as health educators enhances patients' quality of life in areas such as adhering to the Mediterranean diet, reducing consumption of carbohydrates, and improving blood sugar values [47,48].

In view of the great importance of the nurse-patient relationship, consideration should be given to maintaining it over a longer period via electronic means or telephone calls. This approach would reinforce patients' knowledge of their health status (for example, the level of $\mathrm{HbA} 1 \mathrm{c})$, enhance decision-making in this respect, and at the same time, provide cost-benefit advantages for the healthcare system [49]. Indeed, action protocols have been proposed based on this understanding to reduce the risk of complications in patients with poorly controlled DM2 and elevated HbA1c ( $>7 \%)$ [50].

Other studies have shown that increasing the frequency of patients' visits to the nursing consultation improves their quality of life and reinforces lifestyle changes. However, to achieve an effective relationship of trust and to provide the necessary help, it must be established at an early stage. Another crucial question is the patient's motivation, which is directly associated with the likelihood of $\mathrm{HbA} 1 \mathrm{c}$ levels being improved and the enhancement of personal well-being [51,52].

However, opinions are divided. Some researchers have failed to confirm the above considerations, in that statistically significant results were not achieved in patients with elevated levels of $\mathrm{HbA1c}(>8 \%)$, possibly because clear objectives were not established and agreed upon with the patient during which health education consultations with the nurse, [53]. Another inconvenience is that some patients had not achieved long-term improvement by the end of the study period and the intensive follow-up was terminated [54].

Among the ways in which health education may be undertaken, it has been suggested that follow-ups might be improved by "peer training", whereby other patients with DM2 and well acquainted with the condition provide help and advice; however, the assistance and support of qualified nursing staff would still be needed, for example, to correct false beliefs [55-57]. 
Family-focused interventions can also help patients improve self-care and alleviate anxiety. Nevertheless, without the support of appropriate healthcare professionals, it is unlikely to improve $\mathrm{HbA1c}$ levels on its own [58].

The inclusion of cognitive-behavioural therapy as an additional nursing technique may benefit health outcomes by, for example, improving adherence to non-pharmacological treatments [59].

The inclusion of different interventions is important to delay or avoid the inclusion of oral antidiabetics. According to the II Comprehensive Diabetes Plan of Andalusia, oral antidiabetic drugs should be prescribed if after 3-6 months there is no improvement in $\mathrm{HbA1c}$ with adequate adherence to exercise and healthy nutrition [31]. Educational programs, according to previous studies, can improve $\mathrm{HbA1c}$ levels and delay the inclusion of oral antidiabetic drugs or insulin in the treatment of patients with DM2 [60,61]. Other studies showed that oral antidiabetic drugs and insulin improve $\mathrm{HbA1c}$ levels but significantly worsen the quality of life [62]. In addition, patients with this type of treatment require a more specific health education $[63,64]$. Thus, patients must also implement other resources to face different events throughout their disease and be able to maintain metabolic balance [65].

In summary, we believe a simple medical consultation is not enough for patients with DM2 and that a more complex intervention is required to reduce $\mathrm{HbA1c}$ levels and achieve lasting benefit.

\section{Limitations}

The study population was drawn from patients who attended primary-care consultations. This circumstance may have resulted in their presenting a greater willingness to comply with the medical and lifestyle indications provided, thus biasing the results. Furthermore, due to the quasi-experimental design and the intentional sampling, baseline levels of $\mathrm{HbA} 1 \mathrm{c}$ and other pathologies were different between groups. Thus, the results must be accepted with caution.

Another limitation that the period allowed for observing changes in health outcomes may have been insufficient in some cases. Although six months is a substantial period for assessing changes in $\mathrm{HbA1c}$ levels, an intervention lasting 12 months, providing greater intensity and content, might have obtained even better results. As the patient's knowledge and skills are enhanced, health education procedures should be modified accordingly.

\section{Conclusions}

The findings of the study showed that intense health education interventions by nursing staff can make a real contribution to patients with DM2, as their levels of $\mathrm{HbA} 1 \mathrm{c}$ and adherence to good health habits clearly improved. On the other hand, consideration should be given to extending the follow-up provided to maintain long-term benefits. Moreover, appropriate staff training is required to ensure that patient education groups are effectively managed and to personalise care from a holistic perspective, so that patients with DM2 may consolidate and expand their acquired knowledge and habits.

Author Contributions: Conceptualization: M.B.M.-C., G.A.C.-D.l.F., J.L.G.-U.; Methodology: J.L.R.B., G.A.C.-D.1.F., J.L.G.-U.; Software: G.C.-G., M.B.M.-C., J.L.R.-B., L.A.-G.; Validation: M.B.M.-C., G.A.C.-D.1.F., L.A.-G.; Formal analysis: G.A.C.-D.1.F., N.S.-M., G.C.-G.; Investigation: M.B.M.-C., G.A.C.-D.1.F., J.L.G.-U.; Resources: G.A.C.-D.1.F. and L.A.-G.; Data curation: J.L.R.-B.; Writingoriginal draft preparation: M.B.M.-C. and G.C.-G.; Writing-review and editing: M.B.M.-C., N.S.-M. and G.A.C.-D.1.F.; Visualisation: J.L.G.-U. and N.S.-M.; Supervision: L.A.-G. and J.L.G.-U.; Project administration: G.A.C.-D.1.F. and L.A.-G. All authors have read and agreed to the published version of the manuscript.

Funding: This research did not receive external funding. 
Institutional Review Board Statement: This study was conducted in full compliance with the ethical principles of the Declaration of Helsinki and approved by Provincial Ethics Committee of Granada (Spain) (protocol code TES-CEDM-2019).

Informed Consent Statement: All participants gave their signed informed consent and this participation was reflected in their health history.

Conflicts of Interest: The authors declare they have no conflict of interest in this study. The funders had no role in the design of the study, in the collection, analysis or interpretation of data, in the writing of the manuscript or in the decision to publish the results.

\section{References}

1. Inzucchi, S.; Bergenstal, R.; Fonseca, V.; Gregg, E.; Mayer-Davis, B.; Spollett, G.; Wender, R. Diagnosis and classification of diabetes mellitus. Am. Diabetes Assoc. 2010, 33, s62-s69. [CrossRef]

2. Pérez, I. Diabetes mellitus. Gac. Med. Mex. 2016, 152, s51-s55.

3. World Health Organization. Global Report on Diabetes. 2016. Available online: https://www.who.int/publications/i/item/9789 241565257 (accessed on 14 July 2020).

4. Norris, J.M.; Johnson, R.K.; Stene, L.C. Type 1 diabetes-Early life origins and changing epidemiology. Lancet Diabetes Endocrinol. 2020, 8, 226-238. [CrossRef]

5. Mariño, A.C.; Vinces, M.I.; Pico, A.N.; Morales, A.P.; Ruiz, O.X.; Chango, C.M. Factores de Riesgo que inciden en la presencia de diabetes. Recimundo 2018, 2, 189-238. [CrossRef]

6. Petersmann, A.; Müller, D.; Müller, U.A.; Landgraf, R.; Nauck, M.; Freckmann, G.; Schleicher, G. Definition, classification and diagnosis of diabetes mellitus. Exp. Clin. Endocrinol. Diabetes 2019, 127, s1-s7. [CrossRef]

7. Rojo, M.G.; Valdés, S.; Soriguer, F.; Vendrell, J.; Urrutia, I.; Pérez, V.; Ortega, E.; Ocón, P.; Montanya, E.; Menéndez, E. Incidence of diabetes mellitus in Spain as results of the nation-wide cohort di@bet. es study. Sci. Rep. 2020, 10, 1-4. [CrossRef]

8. Valdés, S.; Rojo, M.G.; Soriguer, F. Evolución de la prevalencia de la diabetes tipo 2 en población adulta española. Med. Clin. 2007, 9, 5-352. [CrossRef]

9. Franch, J.; Mata, M.; Mauricio, D. Epidemiología y control clínico de la diabetes mellitus tipo 2 y sus comorbilidades en España (Estudio e-Control). Med. Clin. 2016, 147, 1s-7s. [CrossRef]

10. Dox, I.G.; Melloni, D.J.; Eisner, G.M.; Melloni, J.L. Harper Collins de Bolsillo Ilustrado; Diccionario Médico: Marbán, Spain, 2006.

11. López, A.; Lobo, J.A.; Yanes, W. Epidemiología de la diabetes mellitus. Duazary 2005, 2, 143-146.

12. López, J. La diabetes. Mediterráneo Económico 2015, 27, 239-254.

13. Vounzoulaki, E.; Khunti, K.; Abner, S.C.; Tan, B.K.; Davies, M.J.; Gilles, C.L. Progression to type 2 diabetes in women with a known history of gestational diabetes: Systematic review and meta-analysis. BJM 2020, 369, 1-11. [CrossRef]

14. Factores de Riesgo Para la Diabetes Tipo 2. In National Institute of Diabetes, and Digestive and Kidney Diseases; 2016. Available online: https:/ / www.niddk.nih.gov/health-information/informacion-de-la-salud/diabetes/informacion-general/factoresriesgo-tipo-2 (accessed on 19 August 2020).

15. De Labry, A.O.; Bermúdez, C.; Pastor, G.; Bolivar, J.; Ruiz, I.; Johri, M.; Quesada, F.; Cruz, P.; De los Ríos, M.; Prados, M.A. Effectiveness of an intervention to improve diabetes selfmanagement on clinical outcomes in patients with low educational level. Gac. Sanit. 2017, 31, 41-47. [CrossRef]

16. Eith, E.; Naik, R. Hemoglobin A1C, 2020. Available online: https:/ / www.ncbi.nlm.nih.gov/books/NBK549816/?report=printable (accessed on 15 August 2020).

17. Barranco, R.; Becerra, M.M.; Becerra, V.; Cobo, J.E.; Code, C.; de la Cal, M.A.; García, E.M.; García, M.O.; Jurado, A.M.; Llamas, R. Educación Diabetológica Sanitaria; SEMES: Andalucía, Spain, 2014.

18. Casal, M.; Pinal, I. Guía de práctica clínica de diabetes mellitus tipo 2. Arch. Med. 2014, 10, 1-10. [CrossRef]

19. Catalá, M.; Bataller, A.; Catalá, M.J.; Girbés, J.; Lluch, I.; Sanz, J.; Picó, A.; Mingorance, A.; Ruiz, M.A.; Ampudia, F.J. Plan de Diabetes de la Comunidad Valenciana 2006-2010; Generalitat Valenciana, Conselleria de Sanitat: Valencia, Spain, 2006.

20. Martos, M.B.; Membrive, M.J.; Suleiman, M.; Mota, E.; Cañadas, G.A.; Gómez, J.L.; Albendín, L. Games and health education for diabetes control: A systematic review with meta-analysis. Healthcare 2020, 8, 403. [CrossRef]

21. Martos, M.B.; Velando, M.; Pradas, L.; Suleiman, N.; Cañadas, G.A.; Albendin, L.; Gómez, J.I. Smartphones and apps to control glycosylated hemoglobin (HbA1c) level in diabetes: A systematic review and meta-analysis. J. Clin. Med. 2020, 9, 693. [CrossRef]

22. Escolar-Pujolar, A.; Córdoba, J.A.; Goicolea, I.; Rodríguez, G.J.; Santos, V.; Mayoral, E.; Aguilar, M. The effect of marital status on social and gender inequalities in diabetes mortality in Andalusia. Endocrinol. Diabetes Nutr. 2017, 65, 21-29. [CrossRef]

23. Celada, C.; Tarraga, M.L.; Madrona, F.; Solera, J.; Salmerón, R.; Celada, A.; Panisello, J.M.; Tárraga, P.J. Adherencia a la dieta mediterránea en pacientes diabéticos con mal control. Clin Investig. Arterioscler. 2019, 31, 210-217. [CrossRef]

24. Møller, G.; Andersen, H.K.; Snorgaard, O. A systematic review and meta-analysis of nutrition theraphy compared with diaetary advice in patients with type 2 diabetes. Am. J. Clin. Nutr. 2017, 106, 400-1394. [CrossRef]

25. Bowen, M.E.; Cavanaugh, K.L.; Wolff, K.; Davis, D.; Gregory, R.P.; Shintani, A.; Eden, S.; Wallston, K.; Elasy, T.; Rothman, R.L. The Diabetes Nutrition Education Study Randomized Controlled Trial: A Comparative Effectiveness Study of Approaches to Nutrition in Diabetes Self-Management Education. Patient Educ. Couns. 2016, 99, 1368-1376. [CrossRef] 
26. Mitchell, L.J.; Ball, L.E.; Ross, L.J.; Barnes, K.A.; Williams, L.T. Effectiveness of Dietetic Consultations in Primary Health Care: A Systematic Review of Randomized Controlled Trials. J. Acad. Nutr. Diet. 2017, 117, 1941-1962. [CrossRef]

27. Wang, Y.C.; Wang, C.; Shih, P.W.; Tang, P.L. Analysis of the relationship between lifestyle habits and glycosylated hemoglobin control based on data from a Health Management Plan. Nutr. Res. Pract. 2020, 14, 218-229. [CrossRef] [PubMed]

28. Whitehead, L.C.; Crowe, M.T.; Carter, J.D.; Maskill, V.R.; Carlyle, D.; Bugge, C.; Frampton, C.M.A. A nurse-led education and cognitive behaviour theraphy-based intervention among adults with uncontrolled type 2 diabetes: A randomized controlled trial. J. Eval. Clin. Pract. 2017, 23, 821-829. [CrossRef]

29. Jutterström, L.; Hörnsten, Å.; Sandström, H.; Stenlund, H.; Isaksson, U. Nurse-led patient-centered self-management support improves $\mathrm{HbA1c}$ in patients with type 2 diabetes-A randomized study. Patients Educ. Couns. 2016, 99, 1821-1829. [CrossRef] [PubMed]

30. Rodríguez, G.J.; Córdoba, J.A.; Escolar, A.; Aguilar, M.; Goicolea, I. Familia, economía y servicios sanitarios: Claves de los cuidados en pacientes con diabetes y amputación de miembros inferiores. Estudio cualitativo en Andalucía. Aten. Prim. 2017, 50, 611-620. [CrossRef] [PubMed]

31. Sáez, E.; Risoto, A.; Pozas, A.I.; Cabrera, L.; Cejudo, S.; Baena, F. Tipos de tratamientos prescritos en un grupo de pacientes diabéticos en una farmacia comunitaria. Farm. Comunitarios 2020, 12, 17-21. [CrossRef]

32. Almorós, A.L.; Hang, T.; Peiró, C.; Soriano-Guillén, L.; Egido, L.; Tuñón, J.; Lorenzo, Ó. Predictive and diagnostic biomarkers for gestational diabetes and its associated metabolic and cardiovascular diseases. Cardiovasc. Diabetol. 2019, 18, 1-16. [CrossRef]

33. Plan Integral de Diabetes de Andalucía, 2016. Available online: https://www.juntadeandalucia.es/export/drupaljda/pidma3.pdf (accessed on 24 June 2020).

34. Modhumi, R.M.; Yu, Z.J.; Chi, J.; Ynag, Y.; Liao, Z.; Zhao, Y. From pre-diabetes to diabetes: Diagnosis, treatments and translational research. Medicina 2019, 55, 546. [CrossRef]

35. Dack, C.; Ross, J.; Stevenson, F.; Pal, K.; Gubert, E.; Michie, S.; Yardley, L.; Barnard, M.; May, C.; Farmer, A. A digital selfmanagement intervention for adults with type 2 diabetes: Combining theory, data and participatory design to develop HeLPDiabetes. Internet Interv. 2019, 17, 1-12. [CrossRef]

36. Linkeviciute-Ulinskiene, D.; Kaceniene, A.; Dulskas, A.; Patasius, A.; Zabuliene, L.; Smailyte, G. Increased mortality risk in people with type 2 diabetes mellitus in Lithuania. Int. J. Environ. Res. Public Health 2020, 17, 6870. [CrossRef]

37. Aparecida, E.; Preira, L.; Silva, A.; de Carvalho, A.; de Souza, C.K.; Noll, M. Type 2 diabetes mellitus in class ii and iii obesity: Prevalence, associated factors, and correlation between glycemic parameters and body mass index. Int. J. Environ. Res. Public Health 2020, 17, 3930. [CrossRef]

38. Fitzpatrick, S.L.; Hill, S.; Stewart, K.; Sutherland, J.; DeGross, S.; Brown, T.; Wang, N.Y.; Allen, J.; Cooper, L.A.; Hill, F. Effect of DECIDE (Decision-making Education for Choices In Diabetes Everyday) program delivery modalities on clinical and behavioral outcomes in urban african americans with type 2 diabetes: A randomized trial. Diabetes Care 2016, 39, 2149-2157. [CrossRef] [PubMed]

39. Parsons, S.; Luzio, S.; Bain, S.; Harvey, J.; McKenNa, J.; Khan, A.; Rice, S.; Watkins, A.; Owens, D.R. Self-monitoring of blood glucose in non- insulin treated type 2 diabetes (the SMBG Study): Study protocol for a randomised controlled trial. BMC Endocr. Disord. 2017, 17, 4. [CrossRef] [PubMed]

40. Azevedo, J.; Ragi, N.; Rabelo, C.; Sanches, C.; Di Lorenzo, C.; Silva, G.C.; Lelis, A.; Oliveira, A. Effectiveness of individual strategies for the empowerment of patients with diabetes mellitus: A systematic review with meta-analysis. Prim. Care Diabetes 2018, 12, 97-110. [CrossRef]

41. Meng, W.; Shu, V.W.; Mei, L.; Li, P.; Lee, T.; Wei, L. Health-promotion interventions enhance and maintain self-efficacy for adults at cardiometabolic risk: A randomized controlled trial. Arch. Gerontol. Geriat. 2019, 82, 61-66. [CrossRef]

42. Carrington, M.J.; Zimmet, P. Nurse health and lifestyle modification versus standard care in 40 to 70 year old regional adults: Study protocol of the Management to Optimise Diabetes and metabolic syndrome Risk reduction via Nurse-led intervention (MODERN) randomized controlled trial. BMC Health Serv. Res. 2017, 17, 813. [CrossRef]

43. De la Fuente, M.C.; Cruz, C.; Santi, M.J. Effectiveness of a primary care nurse delivered educational intervention for patients with type 2 diabetes mellitus in promoting metabolic control and compliance with long-term therapeutic targets: Randomised controlled trial. In. J. Nurs. Stud. 2020, 101, 1-8. [CrossRef]

44. Ismail, K.; Winkley, K.; de Zoysa, N.; Patel, A.; Heslin, M.; Graves, H.; Thomas, S.; Stringer, D.; Stahl, D.; Amiel, S.A. Nurse-led psychological intervention for type 2 diabetes: A cluster randomised controlled trial (Diabetes-6 study) in primary care. Br. J. Gen. 2018, 1, 531-540. [CrossRef]

45. Azami, G.; Lam, K.; Ghazali, S.; Salmiah, S.; Aazami, S.; Mozafari, M.; Taghinejad, H. Effect of a nurse-led diabetes selfmanagement education program on glycosylated hemoglobin among adults with type 2 diabetes. J. Diabetes Res. 2018, 1, 1-12. [CrossRef]

46. Ferreira, M.F.; Rolim, C.; Fiore, S.; Farias, R.; Beloli, L.; Perinetto, T.; Luiz, J.; Bauermann, C. Diabetes education in primary care: A randomized clinical trial. Cad. Saúde Pública 2016, 32, 1-10. [CrossRef]

47. Alonso, R.; García, L.; Patino, M.C.; Sánchez, N.; Gómez, M.A.; Recio, J.I. Effectiveness of a multifactorial intervention in increasing adherence to the Mediterranean diet among patients with diabetes mellitus type 2: A controlled and randomized study (EMID Study). Nutrients 2019, 11, 162. [CrossRef] 
48. Valenzuela, M.J.; Fernández, C.R.; Martos Cabrera, M.B.; Gómez-Urquiza, J.L.; Albendín, G.L.; Cañadas de la Fuente, G.A. Dietas bajas en hidratos de carbono para diabéticos de tipo 2. Revisión sistemática. Nutr. Hosp. 2017, 34, 224-234. [CrossRef]

49. Odnoletkova, I.; Ramaekers, D.; Nobels, F.; Goderis, G.; Aertgeerts, B.; Annemans, L. Delivering diabetes education through nurse-led telecoaching. Cost-effectiveness analysis. PLoS ONE 2016, 11, e0163997. [CrossRef]

50. Kobe, E.A.; Edelman, D.; Tarkington, P.E.; Bosworth, H.B.; Maciejewski, M.L.; Steinhauser, K.; Jeffreys, A.S.; Coffman, C.J.; Smith, V.A.; Strawbridge, E.M. Practical telehealth to improve control and engagement for patients with clinic-refractory diabetes mellitus (PRACTICE-DM): Protocol and baseline data for a randomized trial. Contemp. Clin. Trials 2020, 98, 1-11. [CrossRef]

51. du Pon, E.; Wildeboer, A.T.; van Dooren, A.A.; Bilo, H.J.G.; Kleefstra, N.; van Dulmen, S. Active participation of patients with type 2 diabetes in consultations with their primary care practice nurses-What helps and what hinders: A qualitative study. BMC Health Serv. Res. 2019, 19, 814. [CrossRef]

52. Fazio, S.; Edwards, J.; Miyamoto, S.; Henderson, S.; Dharmar, M.; Young, H.M. More than A1C: Types of success among adults with type-2 diabetes participating in a technology-enabled nurse coaching intervention. Patient Educ. Couns. 2019, 102, 106-112. [CrossRef] [PubMed]

53. Mulder, B.C.; van Belzen, M.; Marike, A.; van Woerkum, C.M.J. Quality assessment of practice nurse communication with type 2 diabetes patients. Patient Educ. Couns. 2015, 98, 156-161. [CrossRef] [PubMed]

54. Gorina, M.; Limonero, J.T.; Álvarez, M. Effectiveness of primary healthcare educational interventions undertaken by nurses to improve chronic disease management in patients with diabetes mellitus, hypertension and hypercholesterolemia: A systematic review. Int. J. Nurs. Stud. 2018, 86, 139-150. [CrossRef]

55. Danet, A.; Prieto, M.A.; Gamboa, E.; Ochoa, L.; March, J.C. La formación entre iguales para pacientes con diabetes mellitus 2. Una evaluación cuantitativa y cualitativa en el País Vasco y Andalucía. Aten. Prim. 2016, 48, 507-517. [CrossRef] [PubMed]

56. Deng, K.; Ren, Y.; Luo, Z.; Du, K.; Zhang, X.; Zhang, Q. Peer support training improved the glycemic control, insulin management, and diabetic behaviors of patients with type 2 diabetes in rural communities of central China: A randomized controlled trial. Med. Sci. Monit. 2016, 22, 267-275. [CrossRef] [PubMed]

57. García García, M.A.; Cañadas-de la Fuente, G.A.; González-Jiménez, E.; Fernández Castillo, R.; García-García, I. Educar en conductas sexuales saludables: Una innovación docente en promoción de la salud. Rev. Med. Chil. 2011, 139, 1269-1275. [CrossRef]

58. Wichit, N.; Mnatzaganian, G.; Courtney, M.; Schulz, P.; Johnson, M. Randomized controlled trial of a family-oriented selfmanagement program to improve self-efficacy, glycemic control and quality of life among Thai individuals with type 2 diabetes. Diabetes Res. Clin. Pr. 2017, 123, 37-48. [CrossRef]

59. Tunsuchart, K.; Lerttrakarnnon, P.; Srithanaviboonchai, K.; Likhitsathian, S.; Skulphan, S. Benefits of brief group cognitive behavioral therapy in reducing diabetes-related distress and $\mathrm{HbA1c}$ in uncontrolled type 2 diabetes mellitus patients in Thailand. Int. J. Environ. Res. Public Health 2020, 17, 5564. [CrossRef]

60. Goudswaard, A.N.; Stolk, R.P.; Zuithoff, N.P.A.; de Valk, H.W.; Rutten, G.E.H.M. Long-term effects of self-management education for patients with Type 2 diabetes taking maximal oral hypoglycaemic therapy: A randomized trial in primary care. Diabet. Med. 2004, 21, 491-496. [CrossRef] [PubMed]

61. O'Connor, P.J.; Sperl-Hillen, J.M.; Rush, W.A.; Asche, S.E.; Dutta, P.; Biltz, G.R. Simulated Physician Learning Intervention to Improve Safety and Quality of Diabetes Care: A Randomized Trial. Diabetes Care 2009, 32, 585-590. [CrossRef]

62. Goddjin, P.P.M.; Bilo, H.J.G.; Feskens, E.J.M.; Groeniert, K.H.; van der Zee§, K.I.; Meyboom-de Jong, B. Longitudinal study on glycaemic control and quality of life in patients with Type 2 diabetes mellitus referred for intensified control. Diabet. Med. 1999, 16, 23-30. [CrossRef] [PubMed]

63. Guo, X.H.; Ji, L.N.; Liu, J.M.; Lou, Q.Q.; Liu, J.; Shen, L.; Zhang, M.X.; LV, X.J.; Gu, M.J. Efficacy of structured education in patients with type 2 diabetes mellitus receiving insulin treatment. J. Diabetes 2014, 6, 290-297. [CrossRef] [PubMed]

64. Walker, E.A.; Shmukler, C.; Ullman, R.; Blanco, E.; Scollan-Koliopoulus, M.; Cohen, H.W. Results of a Successful Telephonic Intervention to Improve Diabetes Control in Urban Adults. A randomized trial. Diabetes Care 2011, 34, 2-7. [CrossRef]

65. Siebolds, M.; Gaedeke, O.; Schwedes, U. Self-monitoring of blood glucose-Psychological aspects relevant to changes in HbA1c in type 2 diabetic patients treated with diet or diet plus oral antidiabetic medication. Patient Educ. Couns. 2006, 62, 104-110. [CrossRef] [PubMed] 